\title{
Evaluation of Some Sweet Potato Cultivars for Sauce Processing
}

\author{
Chhama Devi*, Laureate Hynniewta and Surajit Mitra \\ Department of Post-Harvest Technology of Horticultural Crops, Bidhan Chandra Krishi \\ Viswavidyalaya, Mondouri, Nadia District, West Bengal, India \\ *Corresponding author
}

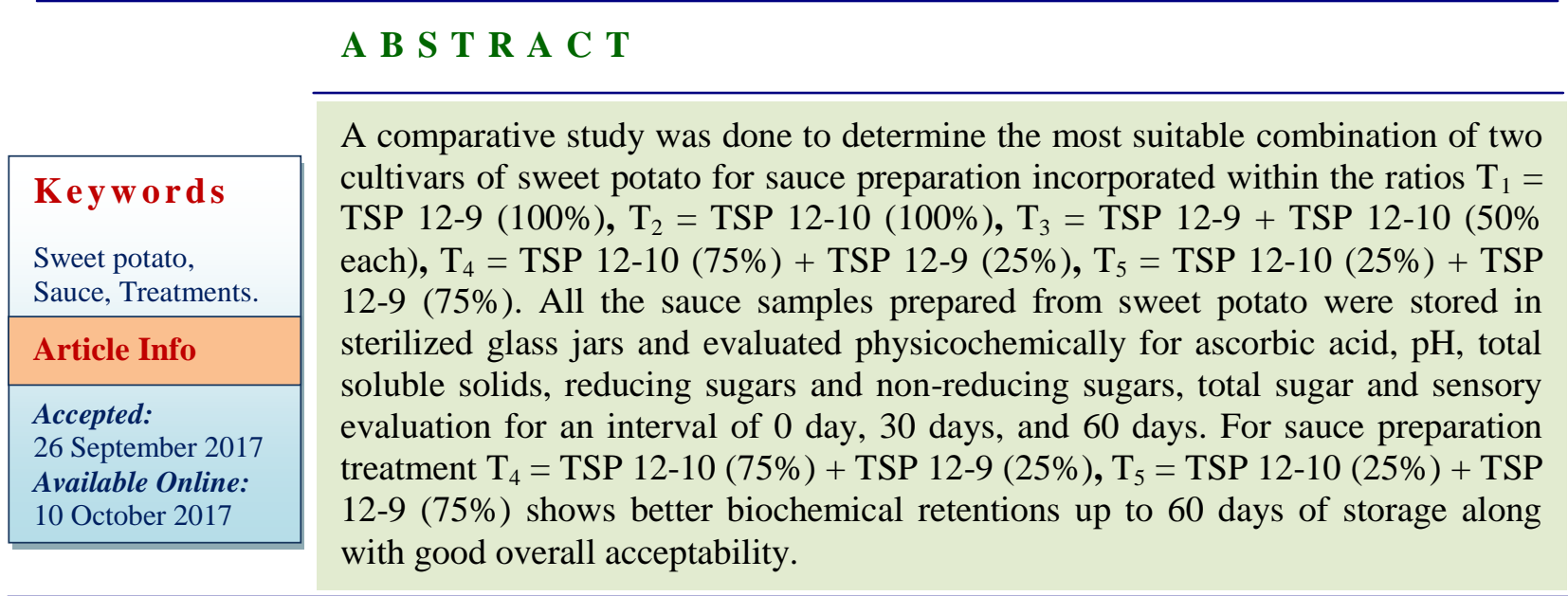

\section{Introduction}

Sweet potato (Ipomoea batatas) is a dicotyledonous plant which belongs to the family of Convolvulacea. It is a minor root crop in tropical Africa and despite its industrial potentials as indicated by its growth in terms of production. Among the root and tuber crops, it is the only one that had a positive per capita annual rate of increase in production in Sub-Saharan Africa. Sweet potato is ranked one of the most important food crop after rice, wheat, potato, maize, and cassava (Shekhar et al., 2015). The total production in India is about 1338 thousand tons and area is 110.63 thousands hectare. In West Bengal the area under sweet potato cultivation is 22.85 thousands hectare and production of sweet potato is about 442.28 thousand tons. Sweet potato plays a major role as a famine reserve for many rural and urban households because of its tolerance to drought, short growth and high yield with limited inputs on relatively marginal soils. Sweet potato is among the world's most important and under-exploited food crops (Scott and Maldonado, 1999; Grant, 2003). Recognizing the great potential of the crop of sweet potatoes in combating malnutrition and food security has resulted in intensified research efforts in recent decades to improve their production and consumption (Queiroga et al., 2007; Laurie et al., 2013). Sweet potato, like other fruits and vegetables, are a rich source of photochemical (Loebenstein and thottappilly, 2009; okuno et al., 1998), 
such as carotenoid, flavonoid and other phenolic compounds. Sweet potato is a starchy commodity whose proximate composition, mineral and vitamin contentparticularly vitamin A (Woolfe, 1992) is comparable to various fruits. This similarity in composition of sweet potato and fruits served as the basis for development of several food products in Asia like candies, jam, juice, and ketchup sauce (Truong, 1992). The organoleptic score for color, aroma, and taste ranged from 3-4 on a hedonic scale.

According to Santis (1995) a sweet potato sauce containing sweet potato $67.93 \%$, tomato juice (15.10\%), vinegar (1.5\%), sugar $(0.75 \%)$, salt $(0.50 \%)$ and spices $(14.19 \%)$ had a good organoleptic score with good viscosity and TSS. The sauce can be stored for 2 months at ambient temperature was also acceptable. The product was rich in calcium (34mg), zinc (36mg) and magnesium (10mg).

\section{Materials and Methods}

The experiment was carried out in the department of Post-Harvest Technology of Horticultural Crops, Faculty of Horticulture, Bidhan Chandra Krishi Viswavidyalaya, Mohanpur, Nadia West Bengal, during the period from 2015-2017. Tubers of sweet potato were obtained from Horticulture Research Station, Bidhan Chandra Krishi Viswavidyalaya, Mondouri, Nadia District, West Bengal.

\section{Preliminary preparation for experiment}

\section{Washing}

Sweet potato tubers harvested after 120 days were washed in tap water after that in distilled water containing $50 \mathrm{ppm}$ of chlorine to get rid of any foreign material that may be adhering to the tuber surface and also to reduce the microbial count.

\section{Drying}

There after the sweet potato tubers were dried with the help of electric fan.

\section{Methodology of Sauce Processing}

\section{Evaluation of physico-chemical properties}

\section{Moisture content (\%)}

The sample was dried in drier at $65^{\circ} \mathrm{C}$ and initial and final weight was recorded by weighing balance.

Final value - initial value $\times 100$

$(\%)$ moisture $=$

Initial value

\section{Dry matter content (\%)}

Dry matter of harvested tubers of different cultivars was recorded in gram after drying the samples in drier at $65^{\circ} \mathrm{C}$ for few hours.

\section{Total soluble solid $\left({ }^{0} \mathbf{B}\right)$}

A total soluble solid was determined by using a Hand Refract meter from the extract of sweet potato tuber harvested at 120 days after planting.

\section{Ascorbic acid (mg/100g)}

Estimated using 2, 6 dichloro-endophenol dye titration method. (Ranganna, 2000). Ascorbic acid reduces the 2, 6-dichlorophenol indophenols dye to a colorless leuco-base.the ascorbic acid gets oxidized to dehydro asccorbic acid.

Though the dye is blue colored compound, the end product is the appearance of pink color. The dye is pink color in acidic medium. Metaphosphoric acid is used as the titrating agent. 


\section{Reducing sugar (\%)}

Sugar level was determined by copper reduction method. (Ranganna, 2000).

Total sugar $(\%)$

Sugar level was determined by copper reduction method. (Ranganna, 2000).

\section{Non reducing sugar $(\%)$}

Non reducing sugar content was determined by deducting the reducing sugar from the total sugar content.

\section{Sensory evaluation}

It was done using the 9 points hedonic score as given by Ranganna (2000).

\section{Results and Discussion}

\section{Total soluble solids $\left({ }^{0} \mathrm{~B}\right)$}

In general, the TSS content in sauce should be stable during storage period.The TSS remains constant may be due to standardization of TSS during the processing. Similar findings were observed by Pruthi et al., (1980) in TSS of tomato ketchup; Bhatnagar et al., (1987) in TSS of tomato ketchup. There was slight difference in TSS content during storage with average mean value of 30.024 during initial days of storage to 30.074 after 60 days of storage.

\section{pH}

In general, there has been significant decrease in $\mathrm{pH}$ in ketchup after 60 days of storage. The $\mathrm{pH}$ was highest in $\mathrm{T}_{1}$ (3.845) after 60 days of storage and minimum in $\mathrm{T}_{5}$ (3.238). The decreasing trend of $\mathrm{pH}$ may be due to biochemical changes taken place amongst the different constituent in sauce hence goes period of sauce. Similar trend was observed by Adsule et al., (1980) in the $\mathrm{pH}$ of tomato bottled juice; Chawla et al., (2003) in the $\mathrm{pH}$ was carrot chutney.

\section{Total sugar content $(\%)$}

In general, the total sugar in sauce recorded gradual increase during storage period. The total sugar was found higher in $\mathrm{T}_{1}$ (22.685) which was followed by $\mathrm{T}_{5}(22.66)$ and $\mathrm{T}_{3}$ (22.655) and $\mathrm{T}_{4}(22.655)$ as being at par with each other after 60 days of storage.

This trend of total sugar (\%) may due to a function of breakdown of insoluble polysaccharides in to simple sugars. Such identical increase in total sugars in various products have been reported by Chattopadhyay et al., (2006) in sweet potato.

\section{Reducing sugar content (\%)}

In general, the reducing sugars in sauce increased with the advancement of storage period. The reducing sugar was highest in $\mathrm{T}_{5}$ $(12.98 \%)$ which was followed by $\mathrm{T}_{2}(12.9 \%)$ as being at par with each other after 60 days of storage.

The increasing, might be assigned to the more conversion on non-reducing sugars into invent sugar through the break down process. The similar results are also observed by Gowda et al., (1994) in reducing sugar of tomato puree at the end of 6 months storage.

\section{Non-reducing sugar content $(\%)$}

The non-reducing sugars in sauce decreased with the advancement of storage period. The non-reducing sugar was highest in $\mathrm{T}_{3}(9.89 \%)$ which was followed by $\mathrm{T}_{4}(9.819 \%)$ and $\mathrm{T}_{1}$ $(9.815 \%)$ as being at par with each other and minimum was found in $\mathrm{T}_{2}$ and $\mathrm{T}_{5}(9.68 \%)$ after 60 days of storage 


\section{(Flow Chart for Preparation of Sweet Potato Sauce)}

Sweet potato tuber

ת

Washing

$\sqrt{3}$

Sorting and trimming

\&

Cutting and chopping

תู

Heating at $70-90^{\circ} \mathrm{C}$ for $3-5$ minutes (to soften)

\&

Pulping or extraction of juice/ pulp

\&

Straining of pulp / juice

$\sqrt{3}$

Cooking pulp with $1 / 3$ quantity of sugar

,

Putting spice bag in pulp and pressing occasionally

Iु

Cooking to $1 / 3^{\text {rd }}$ of original volume of pulp/juice

I)

Removal of spice bag (after squeezing in pulp)

$\sqrt{2}$

Addition or remaining sugar and salt

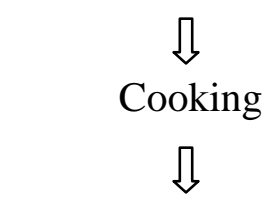

Judging of end point

ת
Addition of vinegar and preservative

\&

Filling into bottles

ก)

cooling

\&

Storage at cool and dry place 
Table.1 Effect on TSS, pH, total sugar, reducing sugar, non reducing sugar, ascorbic acid and sensory quality of sauce during storage

\begin{tabular}{|c|c|c|c|}
\hline \multirow{2}{*}{ Treatments } & \multicolumn{3}{|c|}{ Storage Interval (days) Total soluble solids $\left.\mathbf{(}^{\mathbf{0}} \mathbf{B}\right)$} \\
\cline { 2 - 4 } & $\mathbf{0}$ & $\mathbf{3 0}$ & $\mathbf{6 0}$ \\
\hline $\mathbf{T}_{\mathbf{1}}$ & 30.003 & 30.075 & 30.111 \\
\hline $\mathbf{T}_{\mathbf{2}}$ & 30.028 & 30.078 & 30.083 \\
\hline $\mathbf{T}_{\mathbf{3}}$ & 30.080 & 30.093 & 30.095 \\
\hline $\mathbf{T}_{\mathbf{4}}$ & 30.003 & 30.025 & 30.038 \\
\hline $\mathbf{T}_{\mathbf{5}}$ & 30.005 & 30.020 & 30.045 \\
\hline $\mathbf{M E A N}$ & 30.024 & 30.058 & 30.074 \\
\hline S.Em( $\mathbf{n})$ & 0.0164 & 0.014 & 0.011 \\
\hline C.D.(0.05) & 0.049 & 0.042 & 0.035 \\
\hline
\end{tabular}

\begin{tabular}{|c|c|c|c|}
\hline \multirow{2}{*}{ Treatments } & \multicolumn{3}{|c|}{ Storage Interval (days) pH } \\
\cline { 2 - 4 } & $\mathbf{0}$ & $\mathbf{3 0}$ & $\mathbf{6 0}$ \\
\hline $\mathbf{T}_{\mathbf{1}}$ & 3.973 & 3.938 & 3.845 \\
\hline $\mathbf{T}_{\mathbf{2}}$ & 3.920 & 3.913 & 3.823 \\
\hline $\mathbf{T}_{\mathbf{3}}$ & 3.870 & 3.823 & 3.805 \\
\hline $\mathbf{T}_{\mathbf{4}}$ & 3.888 & 3.818 & 3.805 \\
\hline $\mathbf{T}_{\mathbf{5}}$ & 3.873 & 3.673 & 3.238 \\
\hline MEAN & 3.905 & 3.83 & 3.7 \\
\hline S.Em( $\mathbf{n}$ & 0.009 & 0.072 & 0.008 \\
\hline C.D.(0.05) & 0.028 & $\mathrm{NS}$ & 0.024 \\
\hline
\end{tabular}

\begin{tabular}{|c|c|c|c|}
\hline \multirow{2}{*}{ Treatments } & \multicolumn{3}{|c|}{ Storage Interval (days) Total sugar percentage } \\
\cline { 2 - 4 } & $\mathbf{0}$ & $\mathbf{3 0}$ & $\mathbf{6 0}$ \\
\hline $\mathbf{T}_{\mathbf{1}}$ & 22.140 & 22.218 & 22.683 \\
\hline $\mathbf{T}_{\mathbf{2}}$ & 22.165 & 22.195 & 22.580 \\
\hline $\mathbf{T}_{\mathbf{3}}$ & 22.143 & 22.220 & 22.653 \\
\hline $\mathbf{T}_{\mathbf{4}}$ & 22.075 & 22.213 & 22.655 \\
\hline $\mathbf{T}_{\mathbf{5}}$ & 22.155 & 22.190 & 22.663 \\
\hline $\mathbf{M E A N}$ & 22.136 & 22.20 & 22.64 \\
\hline S.Em( \pm ) & 0.018 & 0.003 & 0.008 \\
\hline C.D.(0.05) & 0.055 & 0.009 & 0.026 \\
\hline & & & \\
\hline
\end{tabular}

\begin{tabular}{|c|c|c|c|}
\hline \multirow{2}{*}{ Treatments } & \multicolumn{3}{|c|}{ Storage Interval (days) Reducing sugar content (\%) } \\
\cline { 2 - 4 } & $\mathbf{0}$ & $\mathbf{3 0}$ & $\mathbf{6 0}$ \\
\hline $\mathbf{T}_{\mathbf{1}}$ & 10.788 & 11.283 & 12.868 \\
\hline $\mathbf{T}_{\mathbf{2}}$ & 11.170 & 11.988 & 12.900 \\
\hline $\mathbf{T}_{\mathbf{3}}$ & 10.955 & 11.608 & 12.758 \\
\hline $\mathbf{T}_{\mathbf{4}}$ & 10.843 & 11.548 & 12.838 \\
\hline $\mathbf{T}_{\mathbf{5}}$ & 10.285 & 11.263 & 12.980 \\
\hline $\mathbf{M E A N}$ & 10.80 & 11.53 & 12.86 \\
\hline S.Em( $\mathbf{(})$ & 0.018 & 0.101 & 0.0152 \\
\hline C.D.(0.05) & 0.054 & 0.306 & 0.045 \\
\hline
\end{tabular}




\begin{tabular}{|c|c|c|c|}
\hline \multirow{2}{*}{ Treatments } & \multicolumn{3}{|c|}{ Storage Interval (days) Non reducing sugar content (\%) } \\
\cline { 2 - 4 } & $\mathbf{0}$ & $\mathbf{3 0}$ & $\mathbf{6 0}$ \\
\hline $\mathbf{T}_{\mathbf{1}}$ & 11.353 & 10.935 & 9.815 \\
\hline $\mathbf{T}_{\mathbf{2}}$ & 10.995 & 10.208 & 9.680 \\
\hline $\mathbf{T}_{\mathbf{3}}$ & 11.188 & 10.613 & 9.895 \\
\hline $\mathbf{T}_{\mathbf{4}}$ & 11.233 & 10.665 & 9.818 \\
\hline $\mathbf{T}_{\mathbf{5}}$ & 11.870 & 10.928 & 9.683 \\
\hline MEAN & 11.33 & 10.67 & 9.78 \\
\hline S.Em( $\mathbf{\pm})$ & 0.027 & 0.10 & 0.0219 \\
\hline C.D.(0.05) & 0.08 & 0.30 & 0.066 \\
\hline & & & \\
\hline
\end{tabular}

\begin{tabular}{|c|c|c|c|}
\hline \multirow{2}{*}{ Treatments } & \multicolumn{3}{|c|}{ Storage Interval (days) Ascorbic Acid Content (mg/100gm) } \\
\cline { 2 - 4 } & $\mathbf{0}$ & $\mathbf{3 0}$ & $\mathbf{6 0}$ \\
\hline $\mathbf{T}_{\mathbf{1}}$ & 27.790 & 26.898 & 25.560 \\
\hline $\mathbf{T}_{\mathbf{2}}$ & 26.925 & 26.805 & 25.525 \\
\hline $\mathbf{T}_{\mathbf{3}}$ & 27.193 & 26.468 & 25.528 \\
\hline $\mathbf{T}_{\mathbf{4}}$ & 27.050 & 26.583 & 25.450 \\
\hline $\mathbf{T}_{\mathbf{5}}$ & 26.890 & 26.553 & 25.055 \\
\hline MEAN & 27.17 & 26.66 & 25.43 \\
\hline S.Em( \pm ) & 0.029 & 0.024 & 0.012 \\
\hline C.D. $(\mathbf{0 . 0 5})$ & 0.089 & 0.073 & 0.037 \\
\hline
\end{tabular}

\begin{tabular}{|c|c|c|c|}
\hline & \multicolumn{3}{|c|}{ Storage Interval (days) Colour } \\
\cline { 2 - 4 } Treatments & $\mathbf{0}$ & $\mathbf{3 0}$ & $\mathbf{6 0}$ \\
\hline $\mathbf{T}_{\mathbf{1}}$ & 8.750 & 8.500 & 8.250 \\
\hline $\mathbf{T}_{\mathbf{2}}$ & 8.500 & 8.250 & 8.250 \\
\hline $\mathbf{T}_{\mathbf{3}}$ & 8.750 & 8.500 & 8.250 \\
\hline $\mathbf{T}_{\mathbf{4}}$ & 9.000 & 8.750 & 8.500 \\
\hline $\mathbf{T}_{\mathbf{5}}$ & 8.750 & 8.500 & 8.500 \\
\hline S.Em $( \pm)$ & 0.23 & 0.27 & 0.266 \\
\hline C.D.(0.05) & $\mathrm{NS}$ & $\mathrm{NS}$ & $\mathrm{NS}$ \\
\hline
\end{tabular}

\begin{tabular}{|c|c|c|c|}
\hline \multirow{2}{*}{ Treatments } & \multicolumn{3}{|c|}{ Storage Interval (days) Taste } \\
\cline { 2 - 4 } & $\mathbf{0}$ & $\mathbf{3 0}$ & $\mathbf{6 0}$ \\
\hline $\mathbf{T}_{\mathbf{1}}$ & 8.750 & 8.500 & 8.250 \\
\hline $\mathbf{T}_{\mathbf{2}}$ & 9.000 & 8.750 & 8.500 \\
\hline $\mathbf{T}_{\mathbf{3}}$ & 8.500 & 8.500 & 8.250 \\
\hline $\mathbf{T}_{\mathbf{4}}$ & 9.000 & 8.750 & 8.000 \\
\hline $\mathbf{T}_{\mathbf{5}}$ & 8.750 & 8.750 & 8.250 \\
\hline S.Em( $\mathbf{(})$ & 0.20 & 0.266 & 0.232 \\
\hline C.D.(0.05) & $\mathrm{NS}$ & $\mathrm{NS}$ & $\mathrm{NS}$ \\
\hline
\end{tabular}




\begin{tabular}{|c|c|c|c|}
\hline \multirow{2}{*}{ Treatments } & \multicolumn{3}{|c|}{ Storage Interval (days) Overall Acceptability } \\
\cline { 2 - 4 } & $\mathbf{0}$ & $\mathbf{3 0}$ & $\mathbf{6 0}$ \\
\hline $\mathbf{T}_{\mathbf{1}}$ & 8.750 & 8.500 & 8.500 \\
\hline $\mathbf{T}_{\mathbf{2}}$ & 9.000 & 8.750 & 8.750 \\
\hline $\mathbf{T}_{\mathbf{3}}$ & 8.750 & 8.250 & 8.750 \\
\hline $\mathbf{T}_{\mathbf{4}}$ & 9.000 & 8.750 & 9.000 \\
\hline $\mathbf{T}_{\mathbf{5}}$ & 8.500 & 8.500 & 9.000 \\
\hline S.Em( \pm () & 0.204 & 0.266 & 0.204 \\
\hline C.D.(0.05) & NS & NS & NS \\
\hline
\end{tabular}

Recipe (Radhakrishnaiah et al., 1987)

\begin{tabular}{|c|c|}
\hline Ingredients & Quantity \\
\hline sweet potato pulp & $750 \mathrm{~g}$ \\
Sugar & $150 \mathrm{~g}$ \\
Garlic & $3 \mathrm{~g}$ \\
Onion & $30 \mathrm{~g}$ \\
Ginger & $18 \mathrm{~g}$ \\
Chili powder & $7 \mathrm{~g}$ \\
Black pepper & $7 \mathrm{~g}$ \\
Cumin powder & $6 \mathrm{~g}$ \\
KMS & $450 \mathrm{mg}$ \\
Vinegar & $185 \mathrm{ml}$ \\
Salt & $40 \mathrm{~g}$ \\
\hline
\end{tabular}

\section{Ascorbic acid content (mg/100gm)}

In general, the ascorbic acid $(\mathrm{mg} / 100 \mathrm{~g})$ in sauce decreased as the storage period increased. The ascorbic acid was found significantly higher in $\mathrm{T}_{1}$ throughout storage periodwhich was $27.79 \mathrm{mg}$ during initial days of storage and $25.56 \mathrm{mg}$ after 60 days of storage, the minimum was found in $\mathrm{T}_{5}$.

It may be due to the oxidation process in head space of package.

This result is in agreement with the study of Pruthi et al., (1980) in tomato ketchup at the end of 12 months; Raina et al., (1980) in canned tomato at the end of 6 months; Chattopadhyay et al., (2006) in sweet potato.
Sensory profile of sweet potato sauce

\section{Colour}

There has been a decline in colour acceptance score for sauce throughout the storage period. The most acceptable colour was recorded in $\mathrm{T}_{4}$ and $\mathrm{T}_{5}$ (8.5) during storage, while while all other treatments was recorded with same score i.e. 8.25 after 60 days of storage. The decline may be attributed to the catalytic effect light on deteriorative in pigment changes either enzymatic or non-enzymatic browning.

These finding are in accordance with that of Kapur et al., (1980) in tomato ketchup; Pruthi (1980) in tomato ketchup. 


\section{Taste}

The consumer acceptance of food product depends on many factors of which taste is the major parameter. In general, the taste score of sauce declined as the storage period increased. The most acceptable taste was found in $\mathrm{T}_{2}$ (8.5) which was at par with $\mathrm{T}_{4}$ (8.0) during the storage period. It may be due to minimum degradative changes of spices added in sauce processing. These results are in conformity with the findings of Raina et al., (1980) in tomato canning (Table 1).

\section{Overall acceptability}

In general, overall acceptability score of sauce was declined throughout the storage period. The highest score of overall acceptability of sauce was exhibited in $\mathrm{T}_{4}$ and $\mathrm{T}_{5}$ (9.00) during the storage. It declined might be due to varietals effect as well as loss of colour, flavour, texture and taste value of ketchup. Such identical findings were also revealed by Raina et al., (1980) in tomato canning; Bhatnagar et al., (1987) in tomato paste and tomato ketchup.

Experiment was conducted by imposing five treatments and four replications. The main objective is to determine the various physical chemical properties of the cultivars. Treatment $\mathrm{T}_{4}$ and $\mathrm{T}_{5}$ shows good biochemical retention and overall acceptability after 60 days of storage.

Thus it can be concluded that processing of sweet potato has to increase shelf life as well as can be used as an alternative to conventional jam and sauce in the market.

\section{References}

Adsule, P. G., Dan, A., Tikko, S. K. and Pal, A. B. (1980). Studies on the evaluation of tomato cultivars for making juice. In.
Fd. Pak., 34 (1): 18-20.

Bhatnagar, D. K., Kainsa, R. L. and Gupta, O. P. (1987). Evaluation of tomato varieties for paste and ketchup making. Haryana Agric. Uni. J. Res., 17 (2): 125-129.

Chattopadhyay, A., Chakraborty, I., Kumar, P. R., Nanda, M. K. and Sen, H. (2006). Uncontrolled storage behaviour of sweet potato. J. Food Sci. Tech., 43 (1): 41-45.

Chawla, P., Ghai, S. and Sachdeva, R. (2003). Study on the nutritionalphysicochemical and organoleptics characteristics of Carrot chutney. $J$. Dairy, Foods and Home Sci., 22 (2): 144- 147.

Gowda, I. N. D., Ramanjaneya, K. H., Anand, N., Sadashiva, A. T. and Tikoo, S. K. (1994). Studies on the physic-chemical characteristics and processing quality of two IIHR tomato varieties in relation to commercial cultivars. J. Food Sci. Tech., 31(2): 126-129.

Grant, V., 2003. Select markets for taro, sweet potato and yam. A report for the Rural Industries Research and Development Corporation (RIRDC). Publication No 03 /052 RIRDC project No UCQ-13A. Online: http://www.rirdc.gov.au.

Kapur, K. L., Singh, V. P., Verma, R. A., Tripathi, M. P. and Garg, R. C. 1980. Screening of tomato varieties for canning and ketchup. Prog. Hort., 11 (4): 57-62.

Laurie, S. M., 2013. Characterization and evaluation of South African sweet potato (Ipomoea batatas (L.) Land races. South Afri. J. of Botany, Amsterdam, 85: 10-16.

Loebenstein, G., and Thottappilly, G. 2009. The sweet potato. Springer, ISBN 978 1-4020-9474.

Okuno, S., Yoshimoto, M., Kumagai and Yamakawa, O. 1998. Contents of beta 
carotene and alpha tocopherol of sweet potato cultivars newly developed for processing purpose. Trop. Agric., 5: 174-176.

Pruthi, J. S., Saxena, A. K. and Teotia, M. S. 1980. Studies on varietal suitability of tomatoes for ketchup manufacture. Indian Fd. Pak., 34(2): 22-30.

Queiroga, R. C. F., 2007. Sweet potato cultivars physiology and yield depending on the harvest period. Horticultura Brasileira, Brasília, 25(3). 371-374.

Radhakrishnaiah S. G., Chikkappaji, K. C., Madiah, N., Nanjunda Swamy, A. M., Raghuvir, K. G., Dhanaraj, S. and Patwardhan, M. V. (1987). Screening of the suitability of Bulgarian varieties of tomatoes for processing into juice, ketchup and tomato paste. Indian $F d$. Pak., 41(1): 7-16.

Raina, B. L., Kalra, C. L., Teotia, M. S. and Rodriguez, R. 1980. Studies on suitability of some tomato varieties for canning. Veg. Sci., 7(1): 60-66.

Ranganna, S., 2000. In: Handbook of Analysis and Quality Control for fruits and vegetable Products. $2^{\text {nd }}$ Edition, Tata McGraw Hill Publication Company Ltd. New Delhi.

Santis, N., Mendoza, F., Moyano, P., Pedreschi, F. and Dejmek, P., 2007.
Soaking in $\mathrm{NaCl}$ solution produce paler potato chips. Food sci. tech., 40: 307312.

Scott, G.J., and Maldonado, L. 1999. CIP sweet potato facts. A compendium of key figure and analyses for 33 important sweet potato producing countries. Peru, Lima International Potato Centre (CIP).

Shekhar, S., Mishra, D., Buragohain, A. K., Chakraborty, S. and Chakraborty, N. 2015. Comparative analysis of phytochemicals and nutrient availability in two contrasting cultivars of sweet potato (Ipomoea batatas L.). Food Chem., 173: 957-965.

Truong, V. D., 1992. Development and transfer of processing technologies for sweet potato in the Philippines, pp. 475480. In: Product Development for Root and TuberCrops. Vol. III-Africa. Scott, G., Ferguson, P.I., and Herrera, J.E. (Eds). Proceedings of the Workshop on Processing, Marketing, and Utilization of Root and Tuber Crops in Africa, held October 26-November 2, 1991 at The International Institute for Tropical Agriculture (IITA), Ibadan, Nigeria. CIP, Lima, Peru. 506p

Woolfe, J. A., 1992. Sweet Potato: An Untapped Food Resource. Cambridge University Press. Cambridge, U. K. 643.

\section{How to cite this article:}

Chhama Devi, Laureate Hynniewta and Surajit Mitra. 2017. Evaluation of Some Sweet Potato Cultivars for Sauce Processing. Int.J.Curr.Microbiol.App.Sci. 6(10): 3257-3265. doi: https://doi.org/10.20546/ijcmas.2017.610.382 